\title{
Network Power Sharing Device: Power Sharing Via USB to Power Port with Output Voltage/Current 17v-19v/4A-4.5A
}

\author{
Oludele Awodele, Oghenerukevwe Onoruvie, \\ Sharon Okoruwa, and Victor Dibia \\ Babcock University, Department of Computer Science and \\ Mathematics, Ilisan-Remo, Ogun State, Nigeria \\ Delealways@yahoo.com, Rukkivie@yahoo.com, \\ Sharonville2003@yahoo.com, Chuvidi2003@yahoo.com
}

\begin{abstract}
The ongoing migration of mobile lifestyles and the increasing capabilities of portable systems will continue to drive demand for more flexible and portable battery charging systems (Brown, 2006). The use of computers has been limited due to lack of constant availability of power issues such as data loss, transaction breakages, data compromise have become major challenges in areas (especially third world countries) where power supply is a problem. Thus there is a need to provide a means of power sharing through USB for computers to share power between two systems (with special emphasis on laptops). Related works/ research has shown that the power sharing between a computer system has only been possible with smaller devices like iPod, since the USB port gives $500 \mathrm{~mA} /+5 \mathrm{~V}$ maximum. This paper describes a device that draws similar voltage and current as the iPod for a destination system after an amplification operation has been carried out on the supplied voltage and power. The power being transferred is initiated by the software driver on detection with destination voltage and current $18 \mathrm{~V}-19 \mathrm{~V} / 4.5 \mathrm{~A}$ with female connector. After construction it will be available to notebook computers system specification and very useful in emergencies and available to all due to its ease of use.
\end{abstract}

Keywords: Network power sharing device (NPSD), DC-DC step-up voltage/current regulator, battery sensing, constant voltage supply, oscillator, driver, female power connector

\section{Introduction}

This research paper describes how a USB and a power port can be used for network power transfer between two systems with the use of a circuit. The Network Power Sharing Device (NPSD) can improve the use, sustenance of computer system in emergencies and in remote locations. The circuit is available to other devices that use voltages and current of the same range

Material published as part of this publication, either on-line or in print, is copyrighted by the Informing Science Institute. Permission to make digital or paper copy of part or all of these works for personal or classroom use is granted without fee provided that the copies are not made or distributed for profit or commercial advantage AND that copies 1) bear this notice in full and 2) give the full citation on the first page. It is permissible to abstract these works so long as credit is given. To copy in all other cases or to republish or to post on a server or to redistribute to lists requires specific permission and payment of a fee. Contact Publisher@InformingScience.org to request redistribution permission. with female power connector/ port (with diameter as of HP). It provides great usefulness in remote locations, third world countries and more locations that encounter power outage challenges. The use of the female power connector is as a result of the production of the recent notebook computers with Hewlett Packard brand of computers. 


\section{Field of the Research}

The proposed invention (Network Power Sharing Device) relates to a method and / or architecture for implementing computer power sharing between two electronic devices with the requirements, generally more particularly to a method and/ or architecture for implementing a device programming configuration for power transfer from Universal Serial Bus (USB) to power port with a circuit. The device could be used to power other devices of the same characteristics not necessarily notebook computers.

The article concentrates on a method (process) for charging of devices with voltage and currents ranging from 18V-19V/4A-4.5A, using a custom built circuit Network Power Sharing Device (NPSD) highlighting its mode of operation in a localized setting.

\section{Related Works}

Highlighted are the research works that have been carried out even though not in direct reference to the present research work been carried out. Battery charge optimizing system is a optimizer circuit that is interposed between a DC bus and a battery of a power supply system, including two converters in parallel: one that can lower the battery voltage below the bus voltage or directly connect the bus to the battery and one that can raise the voltage to the battery above the bus voltage. It requires two series-connected power components are provided on the high current path between the DC bus and the battery, which may increase power dissipation during operation. USB mobile charger, a charging device which charges from any standard USB port and stores an impressive $3400 \mathrm{mAH}$ of power, is used for gadgets with smaller voltage requirements. The system for charging a rechargeable battery of a portable unit rack is a system for charging a rechargeable battery of a portable unit in a rack. The battery is charged at the normal rate upon the control circuit's reception of a valid message, in so far as no other rate has been requested from the unit by means of the message and/or if the control circuit does not select another rate depending on the circumstances (Hulman, 1994). Solar cat solar mobile battery charger charges the cellular phone in 20 minutes only: Output voltage/4.5V 5.0V, -10degreeCent - 60 degree Cent. Of temperature range is an optimum temperature. Mobile battery-charging is a device that has a container and requires two batteries for total and proper performance of the system $(\mathrm{Yu}$, 2006). Ttachima solar mobile battery charger: A mobile battery charger that does not require any power outlet, relying on the sun's rays. The deficiencies associated with the mobile battery charger is the inability of the device to store up energy during the day for it to charge devices when vampires roam (tropical seasons) ("Tachima solar mobile battery charger," 2007), method and circuit for charging battery of portable apparatus is circuit for charging battery portable personal computers are provided with an AC-DC converter or adapter for charging the rechargeable battery of the apparatus with commercial power. The voltage of the apparatus battery is monitored and if it is higher than a reference value, the battery is charged with a high current for a period of time for speed charging. Following the speed charging mode, the battery is intermittently charged with a low current (Tauchi, 1994). A small electronic device has a battery level detection unit for real-time detection of the current battery level and a communication unit for transmitting report data on a detected battery level to another small electronic device, such as a pocket PC device. The receiving small electronic device compares the data with data on its own battery level detected therein and displays the lower battery level data (Aoshima \& Daido, 2006).

\section{Background of the Research}

Over the last few years, the number of portable devices operating from lithium-ion batteries has expanded and the number of features contained in these products has exploded. So, too, has the demand for faster, more convenient and more mobile battery charging systems. Users on-the-go don't always have access to AC power. As they use their portable systems more often, they need 
charging solutions that better conform to their mobile life style. Indicative of this trend is users' growing preference to charge their portable platforms from the USB port on a notebook or desktop computer, or computer peripheral. Charging a portable device via a USB port offers a number of very attractive advantages. USB ports are widely available, so users can recharge their device virtually anywhere. Since a USB port provides bidirectional data transfer, as well as power and ground from the host system, users can charge the battery on their portable device while downloading or updating files at the same time. Portable system designers planning to offer battery recharge capability from a USB port face a number of challenges; not all USB ports are created equal. Some do not comply exactly with the USB 2.0 standard. A compliant USB host source is specified to supply no more than $500 \mathrm{~mA}$, but passive and non-powered ports built into hubs and other computer peripherals are limited to as little as $100 \mathrm{~mA}$. Typically, USB ports feature a current limit protection function that can be set as high as $5.0 \mathrm{~A}$ and as low as $500 \mathrm{~mA}$ (in the case of a host or self-powered hub) or $100 \mathrm{~mA}$ (in the case of a low-power hub or bus). Anyone using aUSB port to charge a battery and power a product must ensure that it does not draw more current than the USB port can deliver or the current limit protection circuit will shut the port down and stop the battery charge cycle. Accordingly, designers must add specific mechanisms to their peripheral product to ensure the USB port will not be overloaded during the charging cycle and undermine system reliability. Additional complications arise if the portable system is designed to operate at the same time as the battery is charging.

In these circumstances, the charging function must share the available port power with the operating system. As port supply capabilities or peripheral load demands change, the system must manage the constant current charge level to the battery in order to ensure valid USB port operation.

Typically, designers have solved these problems by developing complex hardware and firmware solutions. In most cases, this approach allows the designer to manually set two different constant current charge levels, one high and one low, via two external set resistors, and provide an input control to toggle from one level to the other. In portable systems that transfer data via a USB port, the internal USB controller reads the system ID and the system micro-controller adjusts the battery charge current level based on the type of port it is connected to. Alternately, these levels are preset at the factory. While this "high-low" methodology offers a reliable solution, it is far from ideal. First, some portable systems cannot read a host USB port ID. But more importantly, even if the system does offer that capability, it's limited to two discrete charge levels. The high level, typically set to $500 \mathrm{~mA}$, will charge the battery in the shortest possible time. The lower level, usually set to $100 \mathrm{~mA}$ to protect the port, will require an extended charge cycle time. Therefore, if a portable device has a fully capable $500 \mathrm{~mA}$ USB port, but uses any amount of current to operate while the battery is charging, the charge control will be driven to the lower level and the charge cycle will be unnecessarily extended. The difference in the charge cycle time can be dramatic. For example, at the lower level, a $500 \mathrm{~mA} / \mathrm{hr}$ battery could take five hours or more to charge (Brown, 2006).

"Typically charging of devices via computer has been limited to a maximum of $+5 \mathrm{~V}$ voltage and a maximum current that any device is allowed to draw is five units loads (500mA)" (application notes 3607 charging batteries from USB) but in terms of minimum voltage at any USB socket and minimum voltage guaranteed to any device at its USB plug (USB $1.0 \mathrm{spec}$ facts from the spec February 22, 1998) and has resulted in smaller voltage consuming devices like iPod, MP3, MP4, PDA, Camcorder, etc. These devices cannot withdraw a current greater than 500mA.

When the Network Power Sharing Device (NPSD) is connected to the USB an enumeration process identifies the device to determine its load requirement (Applications Notes 3067 charging batteries). 
However the USB ports have been programmed to allow not more than this voltage level $(+5 \mathrm{~V}$ power, maximum current; 500mA) from USB. A USB port can provide $100 \mathrm{~mA}$ to $500 \mathrm{~mA}$ of current at any given time. All USB devices automatically enter a suspend state after $3 \mathrm{mS}$ of bus inactivity. In the suspend state, a device can consume up to an average current of 500microAmp over 1sec. (2.5mA for devices configured as high- power and source of remote wakeup) ("Power consideration for USB applications," n.d.). In the design of the NPSD the standing regulation on USB holds since the device does not disregard the USB standard, except that transfer of power from USB has to be initiated by the switch manually by the use of a set/reset or automatically by the software driver via serial port connector RS232 to the circuit's amplification/regulation unit.

The software driver uses operating system functionality for the execution of the battery level sensing and it sends the signal message to the circuit which acts on the input voltage and current. After amplification and rectification operation has been performed on the input the voltage and current is regulated and ensure that it does not exceed the required current and voltage to avoid destruction that is the device operates a constant voltage output at the regulatory unit "variable input voltage produces a constant voltage with the use of a constant voltage transformer" (Fowler, 2004 , p. 202-218) final power produced at the connector for destination notebook computer is constant which makes it application generally feasible.

In remote locations the sustainability of computer has become greatly questioned as power supply is/ may not be available for charging from main source; the issues of power upsurge could also amount in less use of computer systems. The moving about with weighty power packs will be on the lower side since one can be sure that the device will be of great help for example

Case 1: In a case of power failure and the computer used as main computer if the battery of the system goes down and the device is available, it will only require an extra laptop with good battery life to be able to sustain the main computer, as the computer will act as the source for the other computer; in this case the destination computer is the main computer used for exhibition. Situations like these may occur more rampantly in remote location and third world countries where electricity pose great and might challenge.

Case 2: In cases of emergencies where data is to be withdrawn from a destination computer and the computer has no battery life to carry out this operation the device will just be applicable.

It would be desirable to provide a method and or architecture for implementing computer power sharing with resources with little or no weight and less space consumption making the device very mobile durable and efficient for organization, or data sharing or in real time business.

Ina area of the response of the device on activation, the signal sensing is done in few nanoseconds from the RS232 or manual switching to activate the circuit on connection or detection of low battery cell level, which will be applicable in an emergency to charge a computer system if supposedly contains important and urgent resources needed, without external power supply for the purpose of retaining charge and resources.

A better understanding of the proposed research work can be obtained when the following detailed description of the preferred embodiment is considered in conjunction with the following drawings.

\section{Detailed Description of the Preferred Embodiment}

Figure 1 is a schematic drawing of the operation process of the proposed research work showing the different operations that constitute the function of the circuit (Network Power Sharing Device). 


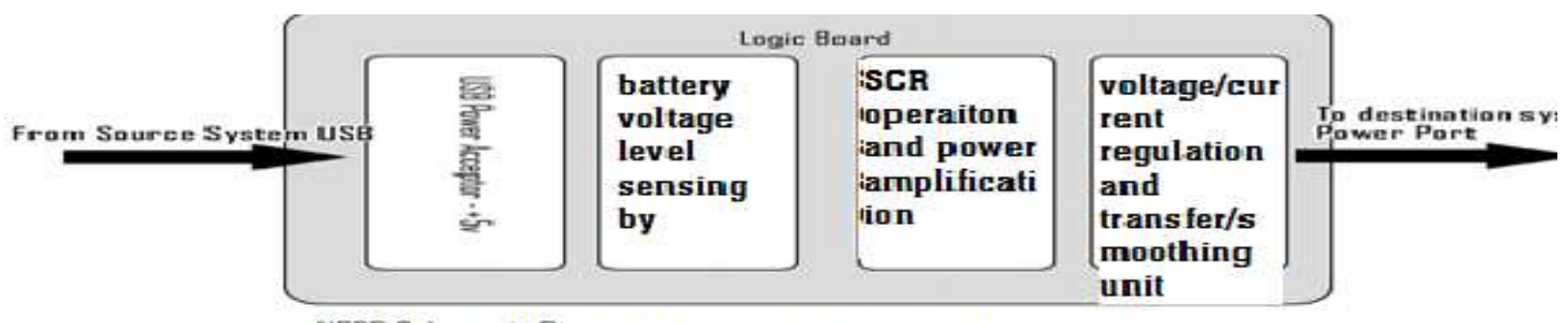

shematic diagram of the Power Sharing device

Figure 1: schematic drawing of the operation process of the proposed research work

Figure 2 is a flow chart of a method (process) describing the preferred embodiment of the proposed research work.

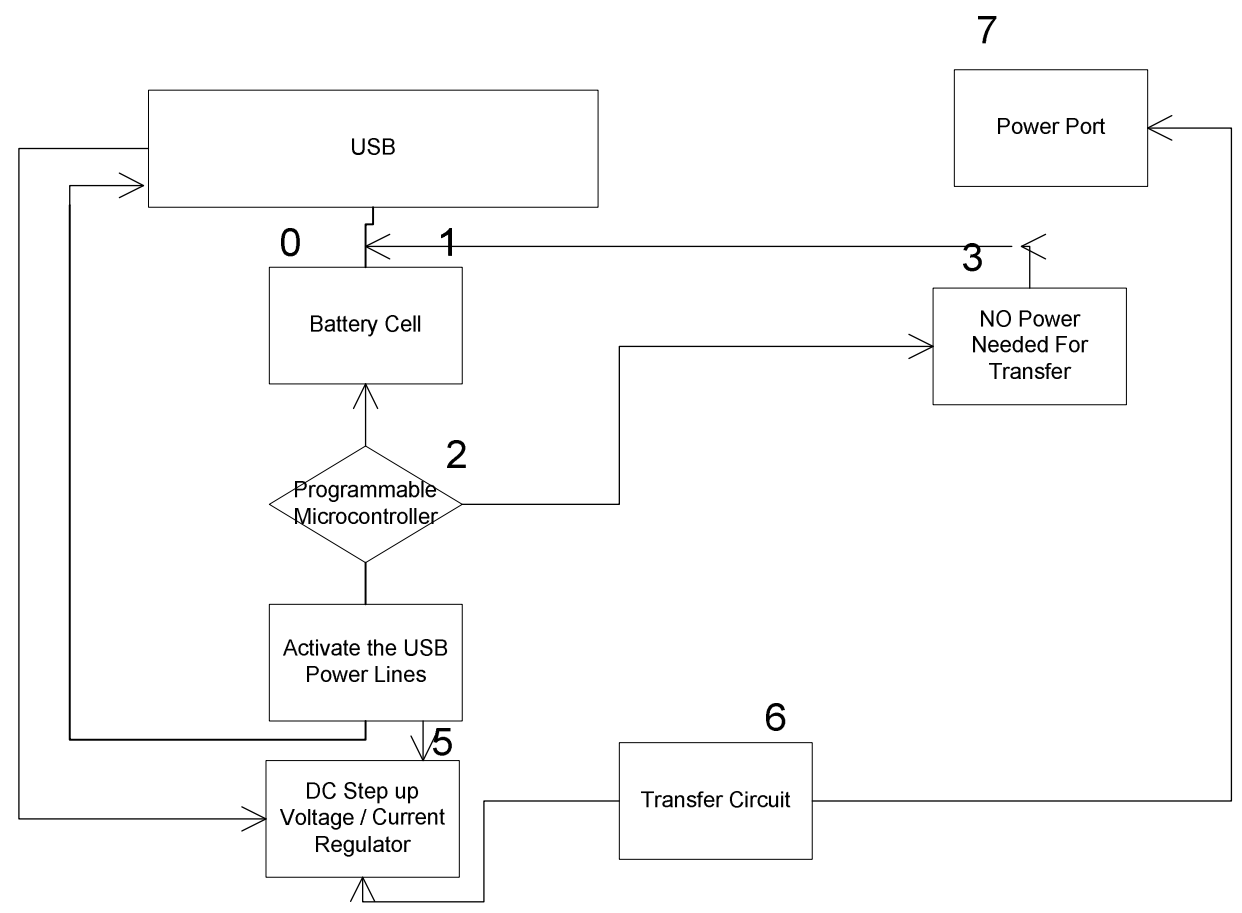

Figure 2: flow chart of a preferred embodiment of the proposed research work

The process may provide a unique programming configuration for computer -to-computer power sharing. It may provide an improve method of charging techniques of computer system with special emphasis on laptops. All that can be dispensed form the computer system on utilization in the area of charging has been $+5 \mathrm{~V}$ maximum, 500mA maximum (Application Notes 3607 charging batteries from USB). The device follows the requested bandwidth and power requirement, using the descriptor information the host computer can set up a communication channel with the peripheral little intervention by the user ("Power consideration for USB Application," n.d.). The device is a high/low power device since its range of voltage/ current intake is from $0.5 \mathrm{~V}$ to $+5 \mathrm{~V} / 100 \mathrm{~mA}$ to $500 \mathrm{~mA}$ insteps of $0.5 \mathrm{~V} /$ unit load (100ma) the specification defines a unit load as maximum $100 \mathrm{~mA}$. The maximum current that any device is allowed to draw is five unit loads 500mA (Application notes 3607; charging batteries from USB). 
The process generally comprises (0) a state, (1) a state (2) a decision state (3) a state (4) a state (5) a state (6) a state, and (7) a state. The circuit connected across the computer systems (source and destination), the software driver for detecting the level of the battery cells ; checks the level of the battery cell on the destination; it makes a decision which either leads to state 3 or state 4 , this process continues as long as the voltage on both side is not lower than the reference voltage, on detection of a voltage lower than the reference voltage that indicates low battery the personal computer sends a signal message to state 4 through serial port RS232, the process may activate the relay which is used as a switch, allowing the voltage/current from the power lines of the Universal Serial Bus port on the cable drawing $+5 \mathrm{v} / 500 \mathrm{~mA}$ from the USB port. While in the state 3 the process enables transfer from the universal serial bus to state 4 which in turn transfer the process to state 5 which activates the process of the voltage/ current $(+5 \mathrm{~V} / 500 \mathrm{~mA})$ amplification for transfer (high power bus powered functions will draw all its power from the bus and cannot draw more than one unit load until it has been configured, after which it can then draw 5 unit loads $500 \mathrm{~mA}$ maximum provided it asked for this in its descriptor. High power bus functions must be able to be detected and enumerated at a minimum $4.40 \mathrm{~V}$. when operating at a full unit load, a minimum Vbus of $4.75 \mathrm{v}$ is specified with a maximum of $5.25 \mathrm{~V}$, the measurements are taken at the upstream plug (USB in a Nutshell)but $5 \mathrm{~V}$ is what is expected on the minimum to be transferred to the state 5 for amplification) to the power port via the transfer circuit, after the amplification of power still in state 5 the process will activate state 6 which is the transfer circuit it contains elements that allow the desired rating of power to be passed to the destination system, this enables the state 7 which is the charge receiver on the system. If the programming state is not enabled then the state 2 may run under normal operating condition. If the programming state is enabled, the state 1 may proceed to state 4 , while in the state 3 , the process may wait for transfer of power from USB power lines (Vbus power, and ground (application notes; charging batteries from USB ) over the communication lines. The state 1 may proceed to state 4 and then to states 5, 6 and to 7 which finalizes the transfer but goes back in the loop to state 4 to continue the process until full. The NPSD is capable of withdrawing voltages as low as $0.5 \mathrm{~V}$ minimum in steps of $0.5 \mathrm{v}$ to maximum of $5 \mathrm{~V}$, currents as low as $100 \mathrm{~mA}$ to maximum $500 \mathrm{~mA}$, the charging process is continuous until there is a break/ termination in the loop either by a manual rest or deactivation of communication between the computer system and the peripheral (state 4 to state 7) then the process will return to state 3 and then to state 0.

The process 1 may be configured with a reset button to ensure that the device is not accidentally activated or transfer of charge as a result of connection of the device (circuit) on the destination and source system. The decision at state 2 is not optional, for example voltage $+5 \mathrm{v}$ cannot be applied externally (to be discussed with further connection in Figure 3 and Figure 4). However the present invention is limited to an internal programming voltage from laptops based on the battery life and flag information of the laptop in use as destination.

Figure 3 the state 2 uses the driver as the interface to checks the voltage level of the battery cell and reports when the battery life is on critical (4), the state 7 is initiated which activates state 3 to accept charge/power from the USB continuing to state 0 transferring $+5 \mathrm{~V} / 100 \mathrm{~mA}-500 \mathrm{~mA}$ to the amplification and rectification unit which steps up voltage / current for the destination device.

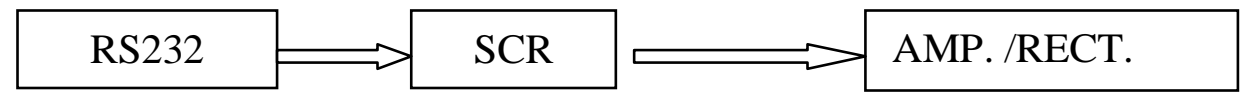

Figure 3: is a block diagram of the switching and signal acceptance operation of the proposed research work

Figure 4 refers to the operation of the DC- AC-DC step up voltage/current regulator the DC-DC controller is both a current and voltage regulator, before now the DC-DC controller is has either 
been a voltage regulator or a current based regulator, a voltage regulator as A8483 1.2MHz stepup converter for display which is a current mode step-up dc-dc controller converter having features as follows output voltage up to $35 \mathrm{~V}$, input voltage $2.5 \mathrm{~V}$ to $10 \mathrm{~V}$, delivers $15 \mathrm{~V}$ at $15 \mathrm{~mA}$ with $2.7 \mathrm{~V}, 350 \mathrm{~mA}$ switch current limit, low noise PWM/ analog dimming (Allegro Microsystems, 2008), the DC- DC controller in the NPSD has features as follows: The preferred IC since it is difficult to purchase as due to the location of this particular design the DC-DC controller will be replaced by a unit referred DC-AC-DC ;Amplification and rectification which can amplify the withdrawn voltage and current up to $25 \mathrm{~V}$ as output voltage and $4.5 \mathrm{~A}$, the current is small since "the size of the copper coil used is dependent on the amount of current required" (Fowler, 2004, pp. 202-218). Some other features of unit includes (i) input voltage of up to 0.5V to $5 \mathrm{~V}$ (ii) output voltage up to $25 \mathrm{~V}$ (iii) $50 \mathrm{HZ}$ frequency generated by oscillator unit (variable resistor, LM555)which is a subsection of the amplification/ rectification unit since the voltage and current amplified is converted to $\mathrm{AC}$ and this is later rectified by a half wave rectifier provides low noise (iv) delivers $25 \mathrm{~V}$ at $500 \mathrm{~mA}$ with $5 \mathrm{~V}$ based on the number of turns used for this design (v) It is a current/voltage mode step up AC-to DC converter. The state 8 continues to state 5 and acts as a supply voltage to state 5 which in turn amplifies the voltage and current from $+5 \mathrm{~V}$ and $100 \mathrm{~mA}-500 \mathrm{~mA}$ (downstream and upstream) to between $18 \mathrm{~V}-19 \mathrm{~V}$, the maximum needed amplification voltage. A DC step up voltage/current regulator. The IC uses a $50 \mathrm{MHz}$ constant switching frequency current mode control scheme to regulate the output voltage or current through the load. The load current is set by selecting the external sense resistor to produce a $10 \%$ of total $\%$ of battery cell at the desired load. The switch current is detected by the internal sense resistor and compared to the error signal (which is as a result of the battery life on critical been detected as by the software driver), pulse width modulated (PWM) control. the duty cycle of the PWM signal is used to regulate the charging current supplied by the charger form the transfer circuit, in particular, the DC value of the PWM signal is used as a reference to control the charging current of the regulator to provide a variable output charging current worth a relatively wide current (Sengupta, Turnbull, Shah, \& Fritz, 1996). As the error signal increases the load current increases to increase output voltage such that FB voltage follows the internal reference voltage.

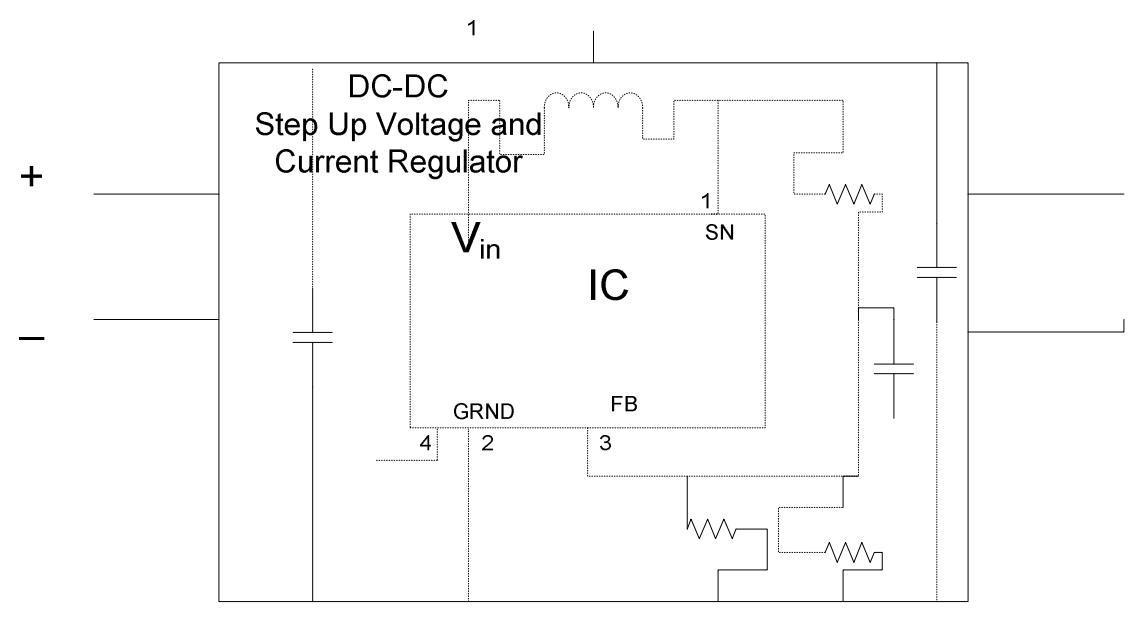

Figure 4: Block diagram of the amplification and rectification unit of the voltage/current fed with the voltage $(+5 \mathrm{~V})$, from the USB of the proposed research work

Figure 5 refers to the transfer circuit in that state after amplification send power through connection lines to the process, which contain a Zener diode and a resistor that is grounded to ensure constant voltage supply of a maximum voltage of $19 \mathrm{~V}$ through the female connector to the destination. 

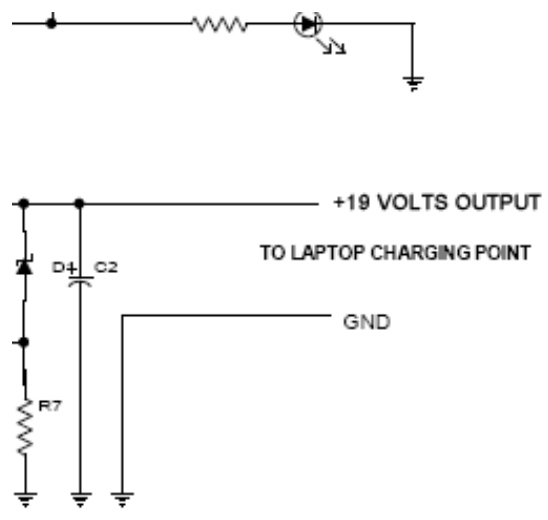

Figure 5: is a circuit diagram of the implementation of the transfer/ smoothing of the voltage $18 \mathrm{~V}-19 \mathrm{~V}$; current $4 \mathrm{~A}-4.5 \mathrm{~A}$ to the destination

The female power connector for transferring to destination is connected to amplification/ rectification (step up voltage/current regulator) and gets its input from there which is then supplied to the destination computer system. The length of the cable is $5 \mathrm{~m}$ the maximum from the USB to the DC- AC-DC step up device.

The USB uses the power lines for its transfer and the data lines are not in use. The operations of the cable is standard and there will be one end using the type B plug; the standard internal wire colors are used in the USB cables, the Vbus (pin1) and ground (pin 4) are connected to the DCAC-DC controller alongside rectification diode and in this is the amplification of the voltage and current carried out. The USB is in suspension mode is the power lines until communication is made from the personal computer.

Figure 6 refers to the internal circuit make up of the device Network Power Sharing Device (NPSD)

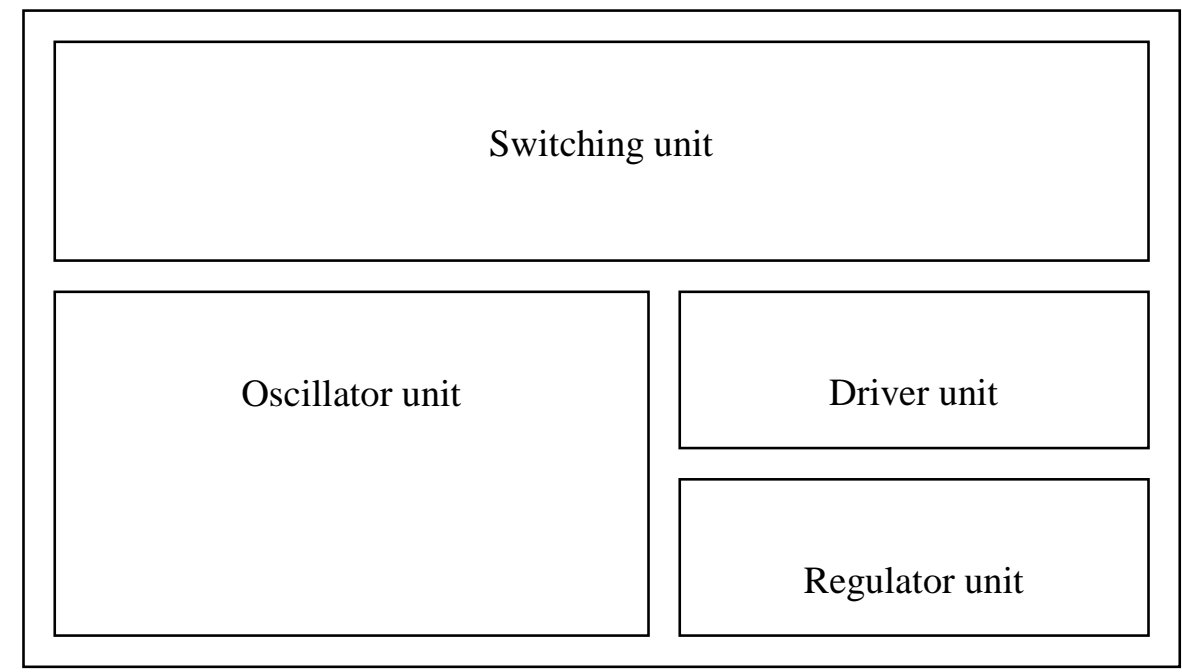

Figure 6: Block diagram of the units of the Network Power Sharing Device (NPSD) 


\section{Limitation on the Research}

Due to the limitation of the possible number of systems to be used at a time with this device and the characteristics of the device, its implementation will be in a localized setting typically of two notebook computers.

As result of different manufacturers of power port the device will be used on devices with female power port as that of HP, since the circuit will be constructed with a female power connector.

\section{Expected Functions of the NPSD}

Highlighted are the expected functions of the network power sharing device (NPSD):

1. The apparatus (NPSD) for providing a source of portable electrical power comprising of (a) a software driver configured to (i) detect voltage of the battery cell on connection (ii) activate the universal serial bus and initiate power transfer (USB) power transfer lines for power transfer; $(b)$ DC-AC-DC step-up voltage/current regulator device configured to (i) step up the input voltage from the universal serial bus to between $18 \mathrm{~V}-19 \mathrm{~V}$ and input current from USB to between $4 \mathrm{~A}$ $4.5 \mathrm{~A}$; female power connector cable for laptop. A list of laptops that accept $18 \mathrm{~V}-19 \mathrm{~V}$ as maximum input voltage and 4A-4.5A as maximum current. Charging current sensing means for sensing the charging current supplied to the destination system while charging the battery.

2. Voltage level sensing means for sensing the voltage of the destination battery cells.

3. A NPSD as recited in claim 2, further including means for sensing the load voltage supplied by said battery cell.

4. A NPSD as recited in claim 1, wherein charging current sensing means include the aspect of the controller to sense the amount of current sent to the destination from the amplification and rectification of the stepped up voltage to the transfer/smoothing unit circuit.

5. A NPSD as recited in claim 1, wherein said controlling means includes means for generating pulse width modulated (PWM) charge controls signal whose duty cycles vary as a function of the charging current supplied to the battery cells and the voltage.

6. A NPSD further include housing for housing device and said controlling means, means for enabling NPSD to be connected to system (laptops)

7. A NPSD as recited in claim 6 , wherein said enabling means include means for enabling to be connected to a predetermined source and destination.

8. A NPSD as recited in claims 7 wherein said enables means includes means for enabling NPSD to be connected to source and destination load without been connected to an external supply charging current, since the device uses little current and voltage for its operation from the withdrawn current and voltage.

9. A NPSD as recited in claim 7charge storage is done by connecting the apparatus to mains for charging to store large amount of charge for the device.

10. A NPSD as recited in claim 7 has means for enabling, provides a manual reset to clear the RS232 and SCR since charge could be sent to the RS232 on connection to the source and destination computers.

11. A NPSD as recited in claim 1 has HP female power connector as connector to the destination notebook computer. 


\section{Recommendation}

The device (NPSD) is applicable to other electronic devices like projectors, scanners, printers, piano that use electricity for its operations, etc, subject to the regulation of the FB pin which is represented by the Zener diode that allow the desired output voltage to pass through the to the destination, in issues of the cost of the circuit the device is relatively less expensive when it comes to it cost compared with cost of a Uninterrupted Power Supply (UPS), the device is relatively less weightier than the UPS and consumes less space making mobility attainable and organization of a larger percentage.

The local consumer will find the device easy to use since application has not much technicality in its usage, because the aim is to reach the local consumer with a cheaper and more efficient device for charging other devices reducing power supply challenges, external battery challenges, provide emergency arrestor.

The device (NPSD) can be maintained by anybody as it does not require any special work in the process. the device can be should be kept from fire, rather should be kept in air free environment since it has mesh to expel heat as a result of the amplification to avoid destruction of the device.

It will be desirable to use such a mobile, reliable, efficient, user - friendly system which acts as a generic solution to power supply challenges.

\section{Further Work and Conclusion}

The device operation is to provide charge for laptop specification, from one computer system (source) via USB to another computer system (destination) via power port.

When this invention is completed it would provide. (i) opportunity for larger voltage devices that follow this specification to be charged via this means and could be a savior in emergencies (ii) reduced risk on destruction of power packs and power ports from upsurge of current (iii) maximum use of computer systems (iv) increased use of computer in remote location (v) less loss of resources. Any person could purchase this device for use with the specification of this device; it may be used on other peripherals that have the specification.

Future work on this research is geared towards expanding the number of systems this device could be used on, alongside increasing the produced voltage/current for destination devices without destroying the USB.

The output voltage to the destination could be increased for larger devices remembering not to affect the USB port.

\section{References}

Allegro Microsystems. (2008). IC switching voltage regulator. Retrieved from http://www.allegromicro.com/en/Products/Part_Numbers/8290/

Aoshima, Y., \& Daido, K. (2006). Small electronic device having battery level detection unit. US Patent issued on November 7, 2006. Retrieved from http://www.patentstorm.us/inventors/Kazuhiko_Daido3108408.html

Brown, D. (2006). Key power management considerations when charging lithium-ion batteries from USB ports. Battery Power Online, 10(6). Retrieved from http://www.batterypoweronline.com/images/PDFs_articles_whitepaper_appros/AdvancedAnalogicTec hnologies.pdf

Charging batteries from USB; Application notes 3607

Fowler, R. (2004). Electricity, principles and applications. McGraw Hill. 
Hulman, F. W. M., (1994). System for charging a rechargeable battery of a portable unit in a rack. US Patent Issued on November 22, 1994. Retrieved from http://www.patentstorm.us/inventors/Fredericus W M Hulman-794661.html

Power consideration for USB applications Rev. A (n.d.). www.quicklogic.com

Sengupta, U., Turnbull, R. R., Shah, R., \& Fritz, B. C. (1996). Computer power supply system. US Patent issued on July 30, 1996. Retrieved from http://www.patentstorm.us/patents/5541490.html

USB 1.0 spec facts from the spec February 22, 1998

USB in a Nutshell http://www.beyoundlogic.org/usbnutshell

Tachima solar mobile battery charger, April 17,

Tauchi, T. (1994). Method and circuit for charging battery of portable apparatus. US Patent Issued on September 27, 1994. Retrieved from http://www.patentstorm.us/inventors/Takaaki_Tauchi766884.html

Trinity Co. Ltd, 1999-2007 Alibaba.com Corporation. Retrieved from http://www.alibaba.com/company/10719986.html

Yu, Tsung-I (2006)

\section{Biographies}

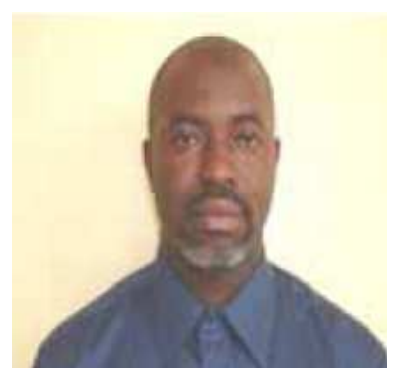

Oludele Awodele is presently a lecturer in the Department of Computer Science and Mathematics, Babcock University, Ilisan-remo, Ogun state, Nigeria. He had his M. Sc in computer science, 2002 at the university of Agriculture Abeokuta, Ph.D. in computer Science and B.Sc Mathematics both at the University of Ilorin 1998 and 1995 respectively. He is currently on his $\mathrm{Ph}$. D programme in computer science in the University of Agriculture Abeokuta. His research areas are software engineering, data communication and artificial intelligence.

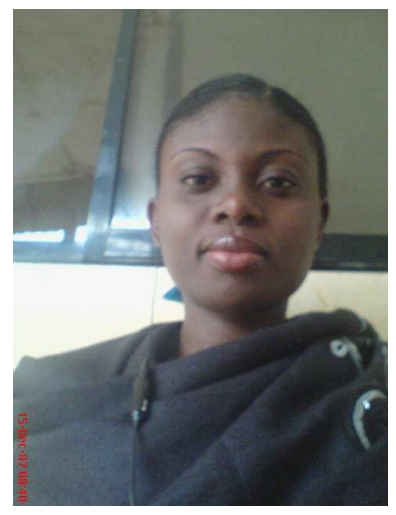

Oghenerukevwe E.L. Onoruvie is presently an undergraduate of computer technology in the Department of Computer Science and Mathematics, Babcock University, Ilisan-Remo, Ogun state, Nigeria. She hopes to graduate June $1^{\text {st }}, 2008$ and have her master's degree (M. Sc) in Information Technology after school. Her area of interest is networking administration, circuit design and analysis. She is a member of IEEE; she is Network + certified. 


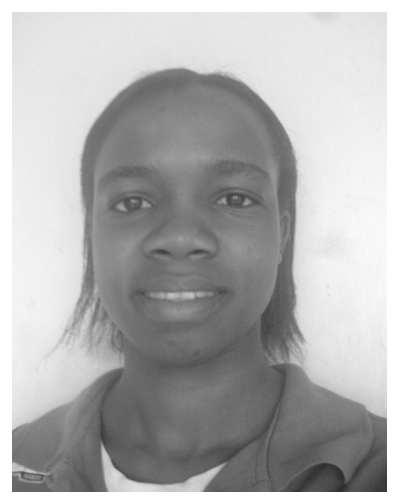

Sharon .O. Okoruwa is an undergraduate presently in Babcock University, Ilisan-Remo, Ogun State, Nigeria. She is studying Computer Technology and she is in her final year. Her area of interest is Hardware and Intelligent Agents.

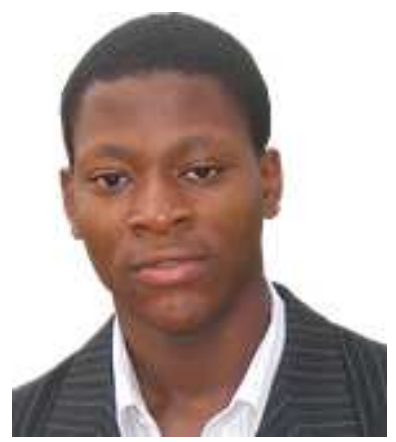

Victor Dibia is a final year student researcher of Computer Science at Babcock University, Ilishan Remo Ogun State. Nigeria. His areas of interest are Software Development, Information System's Security and Control. He is CompTIA Network + Certified. 